\title{
Evaluation of IOR Techniques at the Ula Field
}

\author{
* Jakobsen St. R., * Hegre T. M., ** Peak J., ** Johansen T. \\ * Petec a. s., Norway \\ ** BP Norway Ltd, Norway
}

\begin{abstract}
Copyright 1995, Steering Committee of the European IOR - Symposium.
This paper was presented at the 8th. European IOR - Symposium in Vienna, Austria, May 15 - 17, 1995

This paper was celected for presentation by the Steering Committee. following review of information contained in an abstract submitted by the author(s). The paper, as presented has not been reviewed by the Steering Committee.
\end{abstract}

\section{Abstract}

The Ula reservoir consists of one main reservoir unit which presently is very well swept by injected water, and one upper reservoir unit from which there is significantly lower oil recovery due to its lower permeability.

The paper presents results from a feasibility study which indicates that both horizontal wells and WAG injection would increase oil recovery in the upper, low permeable reservoir unit.

The WAG potential in the upper unit is highly dependent on a number of parameters, such as the presence of high permeable streaks in the main reservoir unit, the $k_{v} / k_{h}$ ratio in the upper unit and gas relative permeability. The study indicates, however, that although WAG potential from the upper reservoir unit is affected by these parameters, the overall WAG potential remains relatively unchanged. As will be discussed below, changes in critical parameters which significantly reduce the upper unit WAG recovery appears to enhance the main unit recovery.

Since the drilling of horizontal wells located close to the top of the structure affects mainly recovery from the upper unit, the potential for this method is more sensitive to changes in upper unit reservoir properties, particulariy the $k_{v} / k_{h}$ ratio, but also well length and location within the upper unit.

\section{Introduction}

The Ula Field is located in the North Sea, $65 \mathrm{~km}$ northwest of the Ekofisk area, see Figure 1. The field was discovered in 1976 and oil production commenced late 1986. Downdip water injection started in 1988. The STOOIP is 138 mill. $\mathrm{Sm}^{3}$ and cumulative production by the end of 1994 was 48 mill. $\mathrm{Sm}^{3}$ out of a total reserve of 69 mill. $\mathrm{Sm}^{3}$.

The Ula main reservoir unit is a fine to medium grained shallow marine sandstone with typical permeability in the range $50 \mathrm{mD}-500 \mathrm{mD}$. The upper reservoir unit is fine grained with relatively low permeability in the range $1 \mathrm{mD}-10 \mathrm{mD}$. The permeability in the upper reservoir unit decreases upwards.

At present, the Ula Field is operated by 6 peripheral water injectors with 8 crestal oil producers. The distance between the water injectors and the producers is typically in the order of $2 \mathrm{~km}$.

With the present well locations, the water flood sweep efficiency and recovery is high throughout the main reservoir unit. The upper unit, which contains approximately $20 \%$ of the total STOOIP, is however poorly swept by the current water injection scheme.

WAG injection is reported to have a significant potential in North Sea reservoirs in general ${ }^{1}$. Simulation studies ${ }^{2}$ and field trials ${ }^{3}$ indicates that the main WAG target is oil at the top of formation which is not recovered by water flooding. Horizontal wells are reported to have a potential for increasing oil production rate and reduce coning in thin low permeable reservoir zones, compared to vertical wells ${ }^{4-7}$.

The paper discusses WAG injection and horizontal wells as possible techniques to enhance recovery from the upper reservoir unit in Ula.

\section{Reservoir and fluid description}

Figure 2 and 3 shows typical permeability distributions with depth near the producers and injectors, respectively, in the sector of Ula covered in the present 
study. The upper reservoir unit is characterised by. its very low permeability. There is pressure communication between the upper and main reservoir units. The upper unit thickness is close to $30 \mathrm{~m}$, while the main reservoir unit thickness is in the order of $120 \mathrm{~m}$.

The oil viscosity is $0.34 \mathrm{cP}$ at reservoir conditions. which ensures a favourable mobility ratio during water flooding. Figures 4 and 5 illustrates typical oil-water and gas-oil relative permeability curves. The gas relative permeability is subject to hysteresis, hence both the drainage and the imbibition scanning curve is included. $S_{\text {orw }}$ and $S_{\text {org }}$ are observed at 0.15 and 0.21 , respectively.

The oil formation volume factor $B_{0}$ is $1.4 \mathrm{~m}^{3} / \mathrm{Sm}^{3}$ at the bubble point pressure 165 bar. Swelling tests indicates that the $B_{0}$ increases to $2.2 \mathrm{~m}^{3} / \mathrm{Sm}^{3}$ at $370 \mathrm{bar}$, indicating that swelling of reservoir oil in the presence of injection gas may be significant.

\section{Simulation model}

The WAG simulation study was conducted using the Eclipse simulation model. The gridblock size in the $x$ direction of the $2 \mathrm{D}$ cross-sectional model was 30 meters in the inter-well area, while the gridblock thickness was typically 2 meters. The 2D model represented approximately $14 \%$ of the total Ula STOOIP.

The simulations were conducted in black oil mode. Dissolution of injection gas in the reservoir oil was modelled, but vaporisation was not taken into consideration. Three phase relative permeability calculations were handled by the default saturation weighted model. Gas relative permeability hysteresis and gas-oil capillary pressure curves were included. The very low permeability part at the top of the upper reservoir unit is represented by one capillary pressure curve, while the lower part of the upper unit and the main unit were represented by a second curve. The capillary threshold pressure between these two regions was 0.03 bar.

The horizontal well simulations were conducted on a 3D sector model to account for the effect of water coning. The appropriate number of gridblocks was found by sensitivity simulations. The gridblocks in the y-direction increase exponential from $3 \mathrm{~m}$ at the well bore to $114 \mathrm{~m}$. The reservoir and fluid properties are identical to the above described $2 \mathrm{D}$ cross sectional model implying that the properties do not change in the y-direction. Figure 5 indicates the position of the injector and the two producers in this model.

\section{WAG Simulation study}

The water injection rate in the $2 \mathrm{D}$ cross sectional model was $1500 \mathrm{Sm}^{3} / \mathrm{day}$, compared to a gas injection rate of $391000 \mathrm{Sm}^{3} /$ day. Simulated WAG injection commenced after 9 years of water injection. The WAG injector is perforated in both the upper and the main unit. Due to the permeability profile with depth, the injection fluids mainly enter the reservoir in the lower part of the main reservoir unit. There was no zone isolation during water or gas injection.

Two of the main sensitivity parameters in the simulation study were WAG cycle length and WAG ratio. WAG ratio is defined as the ratio of water injection period to the gas injection period. As the simulations were run under conditions of voidage replacement to ensure constant reservoir pressure, the WAG ratio was also equal to the ratio of reservoir volume of water injected to the reservoir volume of gas injected.

Table 1 summarises the main results from these simulations. The recovery in the upper reservoir unit is apparently strongly affected by WAG ratio and WAG cycle length. But as revealed from Figure 7, the recovery is a strong function of volume of gas injected and more or less independent of WAG cycle length and ratio.

In the upper unit there are two deviations from a smooth increase in recovery with increasing volume of gas injected. When small volumes of gas were injected, the recovery from WAG injection was reduced compared to pure water flooding. Due to the injectivity contrast, gas enters into the main reservoir only. A minimum volume of gas must be injected in order to saturate the oil in the contacted porevolume. Hence less fluid is available to displace oil from the lower part of the upper unit, compared to waterflooding.

Figure 7 also shows that upper unit recovery from pure gas flooding is lower than for the WAG cases, where only half the amount of gas is injected. This phenomena is related to the upper unit recovery mechanism. Figures 8,9 and 10 show the cumulative water, oil and gas production from the well perforations in the upper reservoir unit, the top of the main unit, and the middle and lower parts of main reservoir unit, from the water flood and base WAG case. It is observed that only minor amounts of gas are produced through the perforations in the upper reservoir unit. It is also observed that the volume of oil produced from this unit during injection is lower than during water injection, despite the fact that the oil recovery is significant higher. The reason is that the oil is produced from the upper reservoir unit by gasoil gravity drainage. As this oil accumulates at the top of the water flooded main reservoir unit, it is displaced by injection water toward the producer. The gravity drainage process is further illustrated in Figure 11. This figure compares the volume of oil produced though the well perforations in the top of the main reservoir unit with the volume of oil actually recovered from this unit

The reduced recovery in the upper reservoir unit during pure gas injection compared to WAG injection, as observed in Figure 7, is probably due to the oil which is 
drained down to the upper main reservoir unit is transported, less effectively to the producer by gas than by the water.

Figure 12 illustrates the WAG flow pattern in the 2D cross-sectional model.

Uncertainty in some critical parameters introduces possible downsides. The influence of changes in residual oil saturation to gas flooding, end point gas relative permeability, $k_{v} / k_{h}$, capillary threshold pressure and horizontal permeability of the most permeable layers were investigated using the simulation model.

A short description of the sensitivities and the main results are given in Table 2 . All changes introduced a reduction in the upper unit oil recovery compared to the base WAG case. However, for all these cases, WAG recovery in the unit remained significantly higher than the water flood recovery. Despite reductions in the upper unit recovery, the overall recovery is only marginally affected by the changes in parameter values. The reason seems to be that reduction in the upper unit recovery is compensated by increased recovery in the main reservoir unit, as more gas is made available. This is particularly true for the case where the vertical permeability is significantly reduced in the upper reservoir unit. Although the upper unit recovery is significantly reduced, the positive impact on main reservoir recovery results in an overall increase.

There are two mechanisms explaining the significant potential in the extensively water flooded main reservoir. As discussed above, injection gas is modelled to significantly swell the reservoir oil. At a reservoir pressure of 370 bar the $B_{o}$ is approximately 1.5 times higher than at the bubble point pressure. Swelling is the main recovery mechanism. In addition there are some effects of reduced oil saturation. Alihough modelled $S_{\text {org }}$ is higher than the $S_{\text {orw }}$, the presence of gas in some layers which are less effectively flooded by water further reduces the remaining oil saturation.

\section{Horizontal wells}

Drilling of horizontal wells in the upper reservoir unit is an alternative approach to increase the oil recovery in the upper unit. Horizontal wells located close to the top of the structure will produce directly from the target unit and water production is expected to be lower compared to vertical wells.

Vertical position, wellbore length and well productivity were key sensitivity parameters. In addition, the influence of vertical permeability in the upper zone was investigated.

The results, in terms of recovery, are not directly comparable with the WAG cases as another vertical producer is added at the crest in these simulations to maintain the waterflood.

Tables 3 and 4 summarise the sensitivities and main results from the horizontal well simulations. It is observed that the horizontal well base case simulation increases the upper reservoir unit recovery in the same order as WAG injection, $16 \%$ compared to $21 \%$. The vertical position of the horizontal well is, however, very critical; the recovery in the upper unit is reduced from $40.7 \%$ to $30.4 \%$ as the horizontal well is lowered from the top part of the upper unit down to the lower, more permeable part. The reduction is caused by earlier water breakthrough from the water flooded main unit. The optimum vertical position of the horizontal well is a trade-off between lower productivity, but reduced water coning in the top of the unit versus higher productivity, but increased water coning in the lower part. Attempts to reduce coning by reducing the liquid production rate was successful, but the lower overall production resulted in a slight reduction in recovery.

As with WAG injection, the upper unit recovery is highly dependent on vertical permeability in this region. Unlike the WAG, however, increased : vertical permeability significantly reduced the upper unit recovery. This was due to increased water coning from the main reservoir unit. The same effect was observed when the transmissibility between two layers below the well was reduced by a factor of 0.005 in order to simulate a possible horizontal barrier in the upper unit due to a thin shale streak.

The main reservoir unit is only slightly affected by the presence of a horizontal well in the upper reservoir unit. In terms of oil recovery, horizontal wells are not as robust as the WAG scheme, because reduced"recovery in the upper reservoir unit is not balanced by upside potential in the main reservoir.

\section{Technical and commercial considerations}

As recalled from Figure 7 , the maximum recovery is obtained at gas injection volume in excess of 700 mill. $\mathrm{Sm}^{3}$. Produced solution gas volume from Ula in the WAG injection period is only 130 mill. $\mathrm{Sm}^{3}$. The volume of gas retained in the reservoir during the 10 years WAG injection period is close to $180 \mathrm{mill} . \mathrm{Sm}^{3}$, indicating that the amount of injected solution gas which would be made available for re-injection is probably marginal. Hence, a substantial volume of gas would have to be imported. This may be achieved in two ways: As the cross sectional model represents close to $1 / 7$ of the total Ula STOOIP, the available solution gas from the entire field would be sufficient to maximise the WAG recovery in a sector of the field. In order to implement the maximum WAG scheme in a larger segment gas must be impored to Ula. Gas imported by laying a pipeline from the nearby Gyda Field might be a solution. Current Gyda solution gas production would be 
sufficient to satisfy the requirement for a full field Ula WAG implementation. The potential for this solution is presently under consideration.

Current Ula gas export is around 85 bar. Gas injection into the reservoir would require $350-450$ bar at the wellhead. This would require significant topside modification, including the commissioning of a new 2stage gas compressor. In addition, it is probable that candidate WAG injection wells would require workover to install suitable completions.

WAG simulations indicated that incremental 'WAG oil' would be produced some 3 years after WAG start-up. Current analysis indicates that such a capital intensive project with long pay-back would be marginal. Topsides modifications and a two-stage compressor are cost estimated to some 25-30 mill. USD. However, the prospect of WAG upside, coupled with other possible synergies (for instance with horizontal drilling, high pressure gas lift etc.) has encouraged the Operator to initiate further WAG studies.

Coiled tubing side-tracks have the potential of providing relatively cheap horizontal wells and multi-lateral drain holes for the upper unit. The cost of a through-tubing side-track with coiled tubing is estimated to some 2.5 mill. USD versus 6 mill. USD for a conventional sidetrack. The technology of coiled-tubing side-tracks is developing fast and could provide a quick and cost effective way of improving the upper unit oil recovery. Project economics show high capital efficiency and payback within one year.

\section{WAG upside potential}

There are some WAG upside potentials not covered in this study. The present producers suffer from high water cut and enhanced, deep gas lift might extend the life of these wells. It has been reported that in certain fields ${ }^{8}$ as much as $60 \%$ of the increased oil potential is related to enhanced lift due to gas production. Though not necessarily significant at Ula, deep gas lift does represents a potential upside.

In the simulation study vaporisation of reservoir oil in contact with injection gas is not taken into consideration. The impact of vaporisation on recovery in the Ula field is uncertain, but represent a further upside.

At a reservoir pressure of $370 \mathrm{bar}$, the injected gas is expected to develop multiple contact miscibility. Studies are presently ongoing to further clarify this aspect. Miscible displacement might introduce additional potentials, for instance reduced $S_{\text {org. }}$.

Subsequent conversion of a horizontal producer to a gas injector has also been considered. The potential is related to less gas consumption to recover the upper unit oil, as gas is more effectively introduced and oil is displaced more directly.

\section{Conclusions}

The simulation study shows that both WAG injection and horizontal wells increases the oil recovery from the upper reservoir unit significantly.

WAG injection also increases the recovery in the main unit.

Project economics for WAG look very marginal due to a high capital investment up front and about three years delay before incremental oil production from WAG is realised.

Horizontal well project economics show high capital efficiency and pay-back within one year.

\section{Acknowledgement}

The authors wish to thank BP Norway and Ula partners for permission to publish the results. We also thank Torbjørn Darre at BP Norway for stimulating discussions and advice during the project.

\section{Nomenclature}

$$
\begin{aligned}
\mathrm{B}_{0} & =\text { oil volume formation factor } \\
\mathrm{L}_{\mathrm{wh}} & =\text { length of horizontal well } \\
\mathrm{k}_{\mathrm{h}} & =\text { horizontal permeability } \\
\mathrm{k}_{\mathrm{v}} & =\text { vertical permeability } \\
\mathrm{k}_{\mathrm{rzo}} & =\text { end-point gas relative permeability } \\
\mathrm{PI} & =\text { productivity index } \\
\mathrm{P}_{\mathrm{c}, \mathrm{hr} .} & =\text { capillary threshold pressure } \\
S_{\mathrm{org}} & =\text { residual oil saturation to gas flooding } \\
S_{\text {orw }} & =\text { residual oil saturation to water flooding } \\
Q_{o, \max } & =\text { maximum oil production rate }
\end{aligned}
$$

\section{References}

1 Hinderaker et. al., "IOR Resource Potential of Norwegian North Sea Sandstone Reservoirs", paper presented at the 6th European Symposium on Improved Oil Recovery, Stavanger, Norway, 21-23 May, 1991.

2 Olsen G. et.al., "Evaluation of the Potential Application on the WAG Process in a North Sea Reservoir", paper presented at the 6th European Symposium on Improved Oil Recovery, Stavanger, Norway, 21-23 May, 1991.

3 Dalen V. et.al., "A WAG Injection Pilot in the Lower Brent Formation at the Gullfaks Field", paper presented at the 7th European Symposium on Improved Oil Recovery, Moscow, Russia, 27-29 October, 1993. 
4 Broman Jr. W.H. et.al.,"Horizontal Well Operations at Prudhoe Bay", paper presented at the International Meeting on Petroleum Engineering, Beijing, China, 24.27 March 1992.

5 Pucknell J.K. and Broman W.H., "An Evaluation of Horizontal and High-Angle Wells Drilled in Prudhoe Bay After Five Years of Production", paper presented at the 68th Annual Technical Conference and Exhibition of the SPE, Houston, Texas, 3-6 October 1993.

6 Macdonald C.J., "Horizontal Wells: An Application in the North Sea", paper presented at the SPE European Petroleum Conference, London, UK, 16-19 October, 1988.

7 O'Bryne D.K., "Reservoir Engineering Aspects of the North Brae Horizontal Well", paper presented at the Offshore Europe Conference, Aberdeen, UK, 3-6 September, 1991.

8 G. Chenoweth, "Field WAG Demonstration in South Brae", paper presented at the Best Practices for Improved Oil Recovery Conference, London, UK, 10th November, 1993.

Tables

Table 1. WAG simulations, WAG ratio and cycle length.

\begin{tabular}{|c|c|c|c|c|}
\hline $\begin{array}{l}\text { WAG } \\
\text { cycle } \\
\text { length }\end{array}$ & WAG ratio & $\begin{array}{l}\text { Volume gas } \\
\text { injected }\end{array}$ & $\begin{array}{l}\text { Recovery } \\
\text { upper unit }\end{array}$ & $\begin{array}{l}\text { Recovery } \\
\text { main unit }\end{array}$ \\
\hline (months) & & $\left(10^{6} \mathrm{Sm}^{3}\right.$ & (\% OOIP) & (F OOIP) \\
\hline & water ini. & 0 & 21.0 & 73.6 \\
\hline 12 & 1 & 25.2 & 41.8 & 78.0 \\
\hline 12 & 3 & 12.6 & 31.6 & 79.7 \\
\hline 12 & 11 & 4.2 & 21.1 & 77.6 \\
\hline 24 & 3 & 25.2 & 30.8 & 79.4 \\
\hline 24 & 7 & 12.6 & 24.1 & 78.7 \\
\hline 24 & 23 & 4.2 & 16.9 & 74.8 \\
\hline 120 & 19 & 2.5 & 17.1 & 76.9 \\
\hline 120 & 2 as ini. & 50.3 & 33.9 & 74.8 \\
\hline
\end{tabular}

Table 2. WAG simulations, reservoir and fluid properties.

\begin{tabular}{|c|c|c|c|}
\hline Case & $\begin{array}{l}\text { Recovery } \\
\text { upper unit }\end{array}$ & $\begin{array}{l}\text { Recovery } \\
\text { main unit }\end{array}$ & $\begin{array}{l}\text { Recovery. } \\
\text { upper and } \\
\text { main unit }\end{array}$ \\
\hline & (4 OOIP) & (द OOIP) & (9. OOIP) \\
\hline Water injection & 21.0 & 73.6 & 61.1 \\
\hline WAG base case & 41.8 & 80.0 & 70.9 \\
\hline $\begin{array}{l}S_{\pi} \text { increased from } 0.21 \text { to } \\
0.28\end{array}$ & 33.3 & 79.8 & 68.7 \\
\hline $\begin{array}{l}k_{T_{0}} \text { reduced from } 0.58 \text { to } \\
0.35\end{array}$ & 31.7 & 80.6 & 69.0 \\
\hline $\begin{array}{l}\mathrm{K}_{\mathrm{t}} \text { in high permeable } \\
\text { lavers mult. with factor } 3\end{array}$ & 29.6 & 80.8 & 68.6 \\
\hline $\begin{array}{l}P_{c . s m} \text { increased from } 0.03 \\
\text { to } 0.2 \text { bar. }\end{array}$ & 28.3 & 80.2 & 67.9 \\
\hline $\begin{array}{l}\mathrm{K} v / \mathrm{Kh} \text { reduced from } 0.2 \\
\text { to } 0.01 / 0.1\end{array}$ & 27.8 & 86.6 & 72.6 \\
\hline
\end{tabular}

Table 3. Horizontal well simulation, well position and length

\begin{tabular}{|c|c|c|c|}
\hline Case & $\begin{array}{l}\text { Recovery } \\
\text { upper unit }\end{array}$ & $\begin{array}{l}\text { Recovery } \\
\text { main unit }\end{array}$ & $\begin{array}{l}\text { Recovery, } \\
\text { upper and } \\
\text { main unit }\end{array}$ \\
\hline & (\% OOIP) & (\% OOIP) & (9.0OIP) \\
\hline $\begin{array}{l}\text { Waterflood, } \\
\text { vert. well base case }\end{array}$ & 25.1 & 75,1 & 63,3 \\
\hline $\begin{array}{l}\mathrm{L}_{\mathrm{b}}=1000 \mathrm{~m}, \mathrm{Z}=4^{*} \text { ), } \\
\text { hor, well base case }\end{array}$ & 40,7 & 74.2 & 66,3 \\
\hline$L_{w}=1000 \mathrm{~m} \cdot \mathrm{Z}=9$ & 30.4 & 74.7 & 64.2 \\
\hline $\mathrm{L}_{\mathrm{w}}=1000 \mathrm{~m} . \mathrm{Z}=2$ & 40,4 & 74.1 & 66,1 \\
\hline$L_{\alpha}=500 \mathrm{~m}, \mathrm{Z}=4$ & 29.7 & 74.0 & 63.5 \\
\hline
\end{tabular}

Table 4. Horizontal well simulation, well constraints and reservoir properties.

\begin{tabular}{|c|c|c|c|}
\hline Case & $\begin{array}{l}\text { Recovery } \\
\text { upper unit }\end{array}$ & $\begin{array}{l}\text { Recovery } \\
\text { main unit }\end{array}$ & $\begin{array}{l}\text { Recovery, } \\
\text { upper and } \\
\text { main unit }\end{array}$ \\
\hline & (\% OOIP) & (\% OOIP) & (\% OOIP) \\
\hline Hor. well base case & 40.7 & 74.2 & 63.3 \\
\hline $\begin{array}{l}\text { Q amax, reduced from } 1600 \\
\text { to } 320 \mathrm{Sm}^{3} / \mathrm{d}\end{array}$ & 40,1 & 74,1 & 66,0 \\
\hline PI increased by factor 2 & 38.9 & 74,1 & 65.7 \\
\hline$k_{n} / k_{+}$reduced by factor 10 & 47.0 & 73.7 & 67.4 \\
\hline$k_{v} / k_{+}$increased by factor 2 & 38.8 & 74.5 & 66.0 \\
\hline $\begin{array}{l}\text { Reduced transmissibility } \\
\text { between } 2 \text { lavers. *) }\end{array}$ & 48,1 & 73,7 & 67.7 \\
\hline
\end{tabular}

-) Layers are locared in the upper unit, below the horizontal well.

\section{Figures}

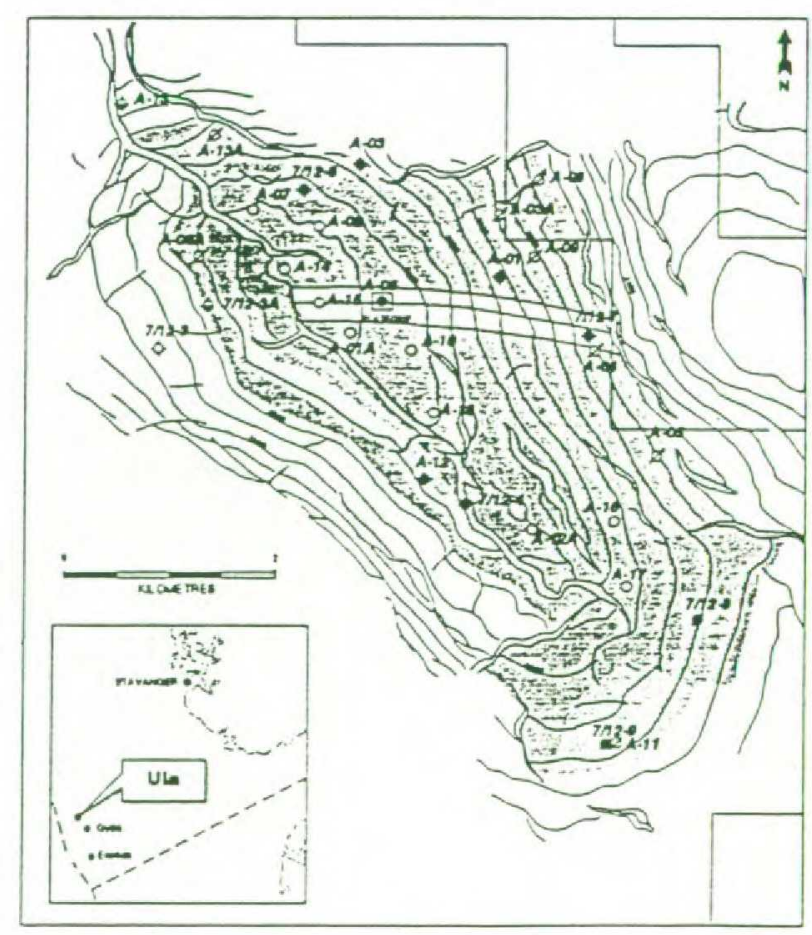

Figure 1. Location of the UTa Field, and the top reservoir map 


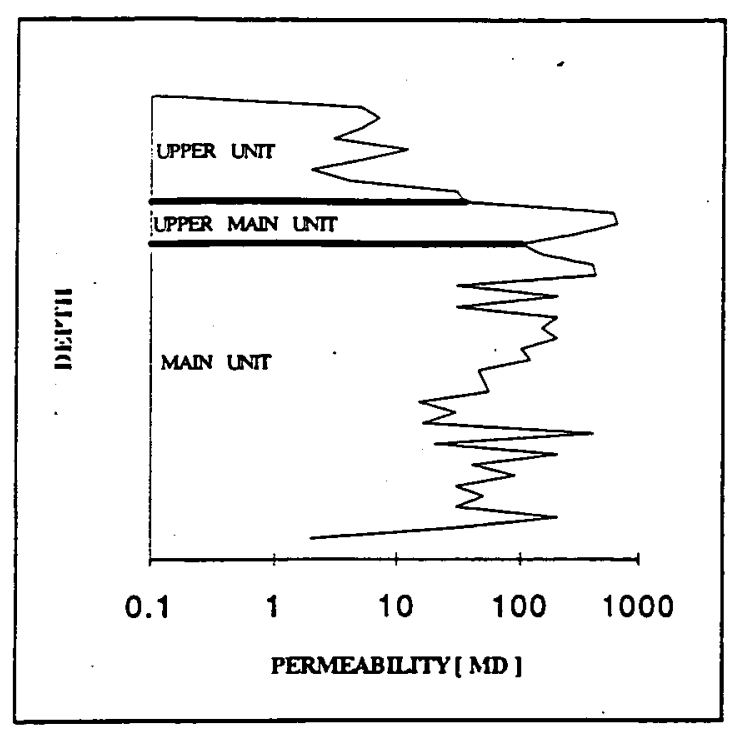

Figure 2. Permeability with depth near producer.

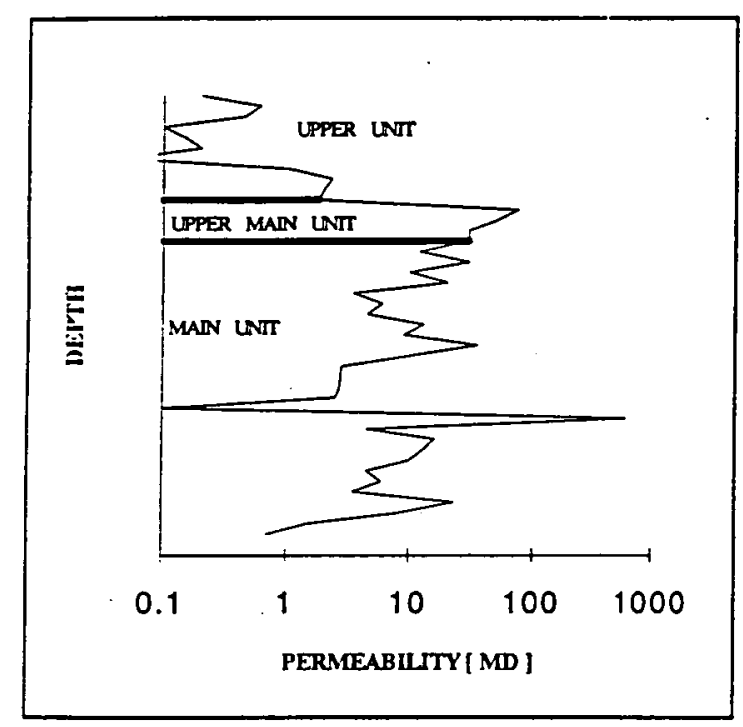

Figure 3. Permeability with depth near injector.

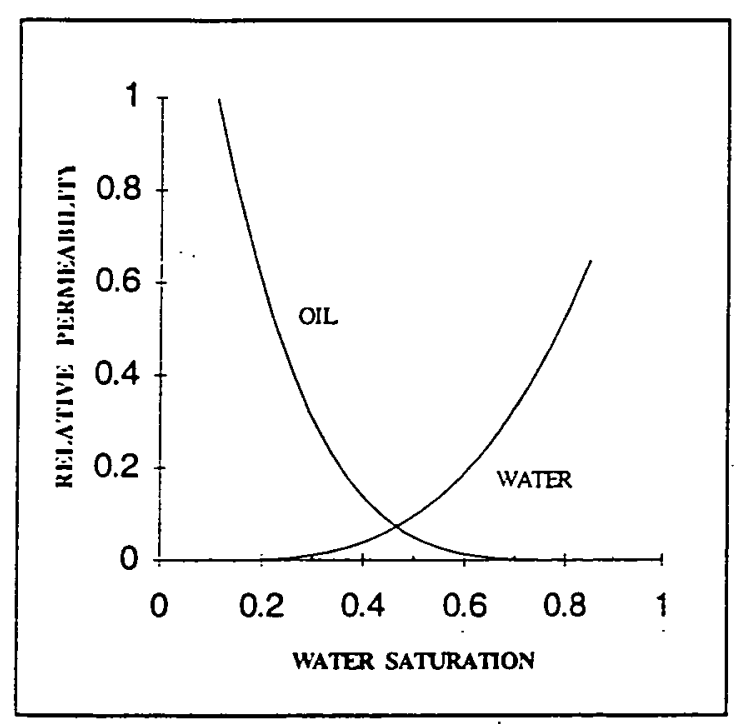

Figure 4. Oil - Water relative permeability

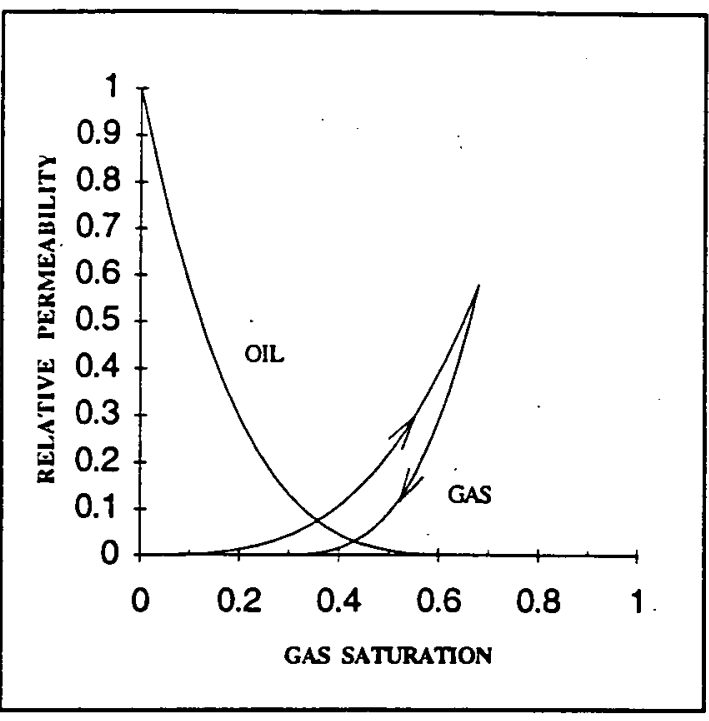

Figure 5. Gas - Oil relative permeability

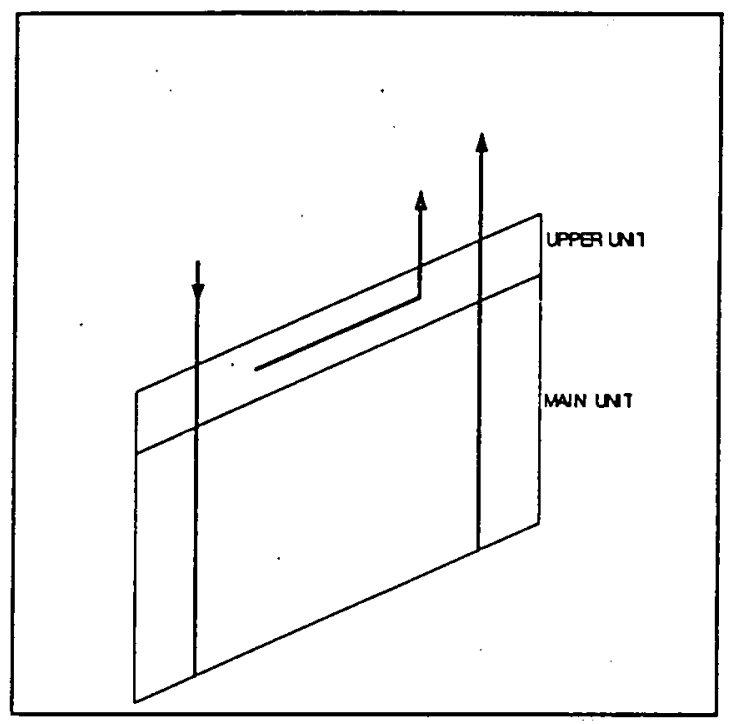

Figure 6. Illustration of horizontal well position.

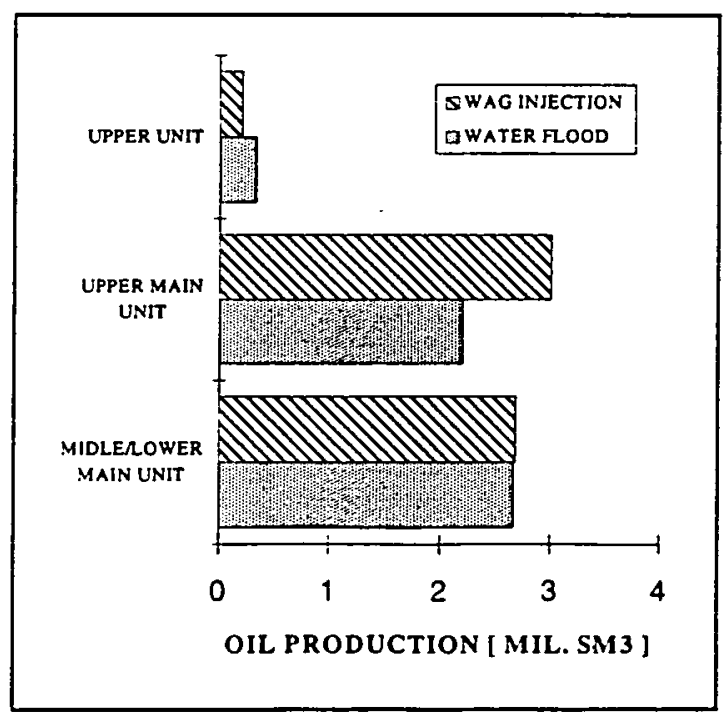

Figure 8. Oil production at well connections in upper and main unit. 


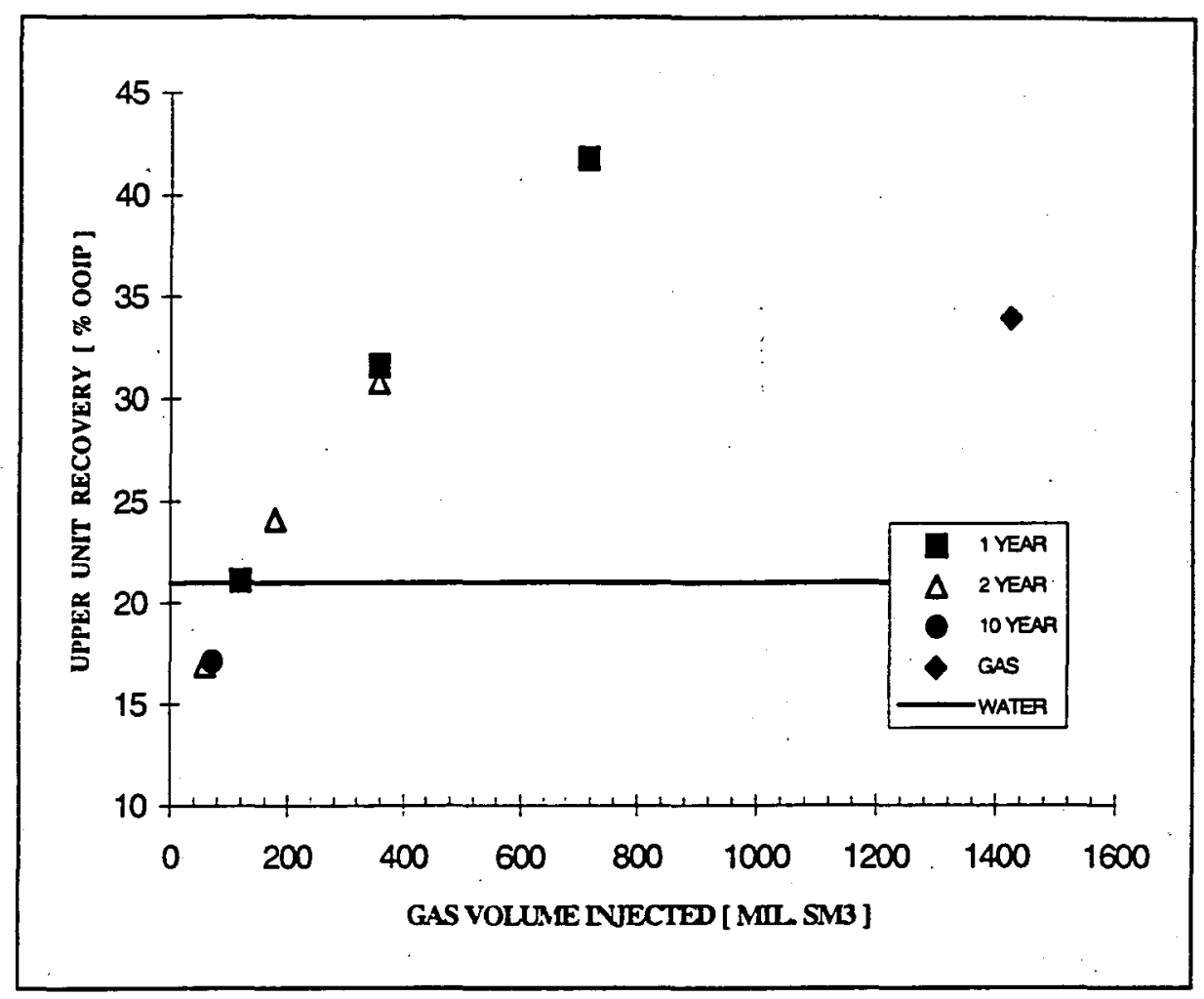

Figure 7. Oil recovery in upper unit as a function of volume of gas injected for 1,2 and 10 year gas cycies. The figure also indicates water and gas flood recovery.

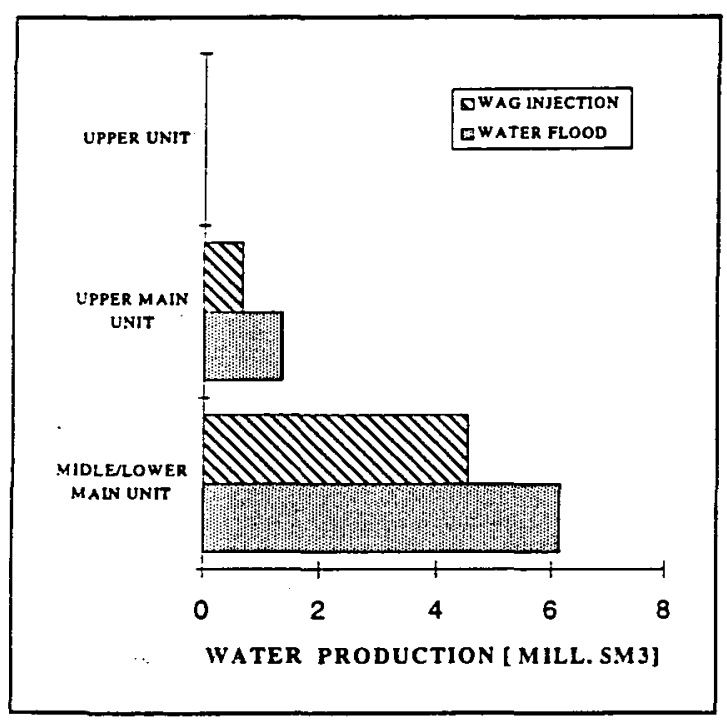

Figure 9. Water production at well connections in upper and main unit.

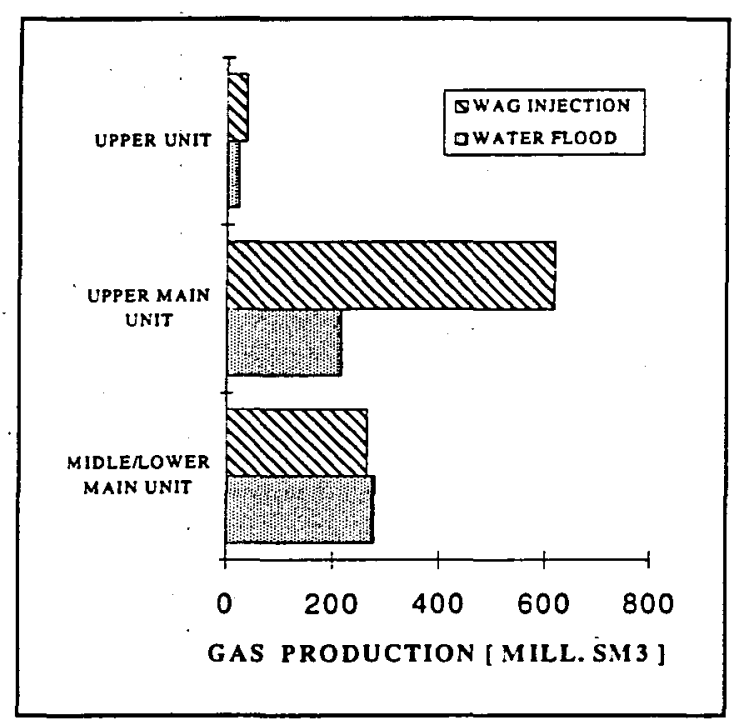

Figure 10. Gas production at well connections in upper and main unit. 


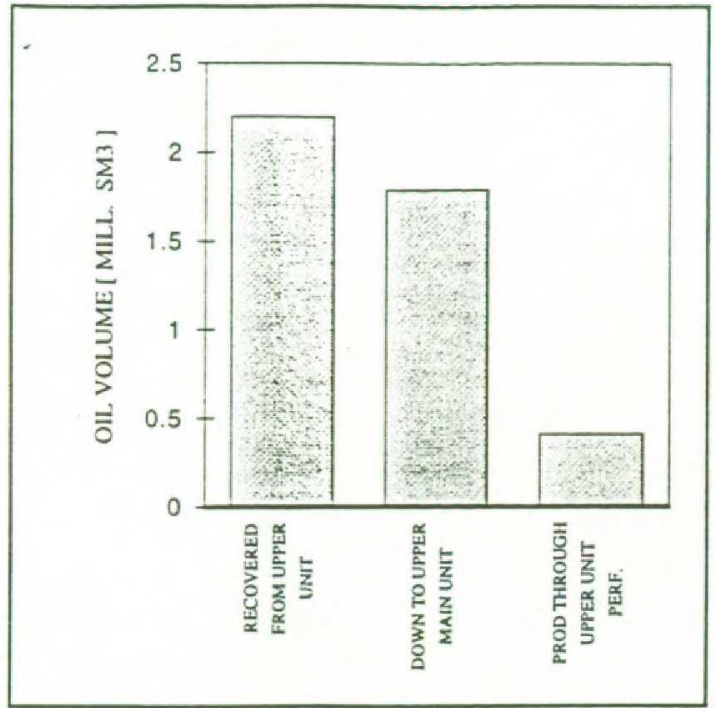

Figure 11. Volume of oil recovered and produced from upper unit.

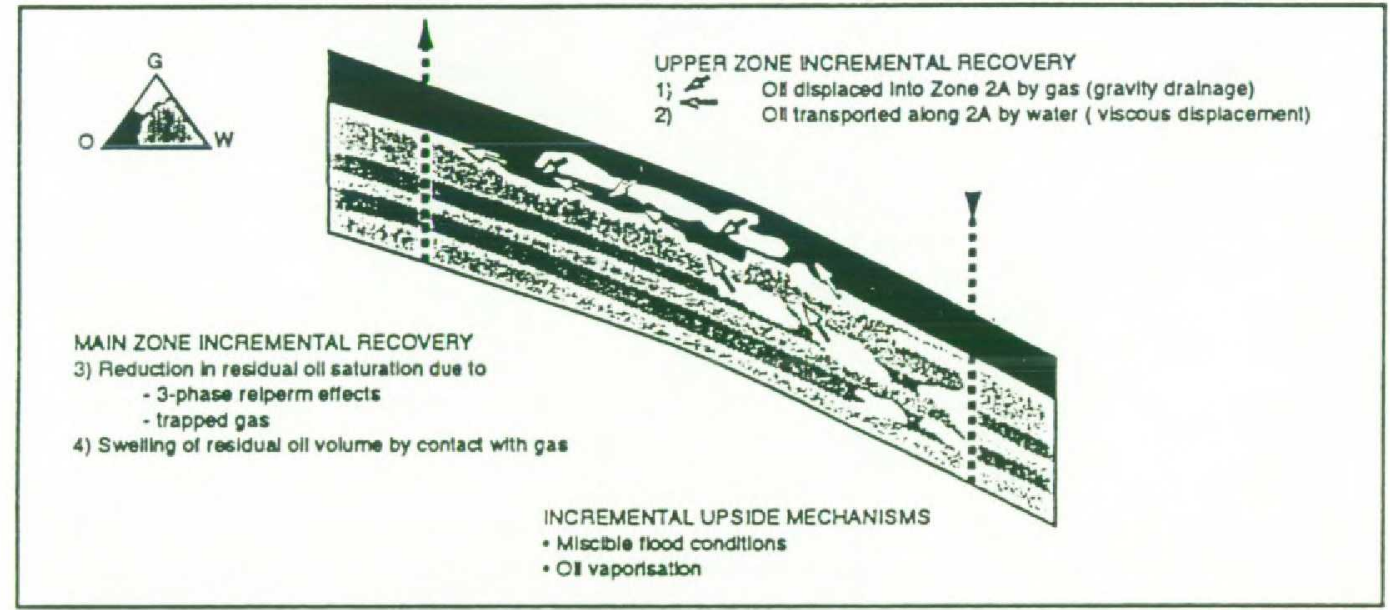

Figure 12. Illustration of the upper unit recovery mechanism. Upper unit oil is gravity displaced by gas to upper main unit, from which the oil is viscous displaced by water to producer. 